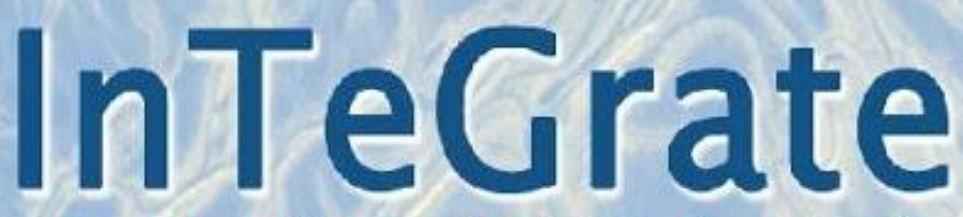

Interdisciplinary Teaching about Earth

for a Sustainable Future

\title{
Lessons Learned from the InTeGrate Project: Supporting Postsecondary Faculty in Their Design of Curricular Materials Connecting Geoscience and Societal Challenges
}

David Steer (University of Akron), Aida Awad*(To The Cloud EDU), Leilani Arthurs (University of Nebraska-Lincoln), Joshua Caulkins (University of Rhode Island), Karen Viskupic (Boise State University), Ellen Iverson (Science Education Resource Center), Carol Baldassari (PERG: Endicott College), Cathryn Manduca (Science Education Resource Center)

* Presenting author This work is supported by a National Science Foundation (NSF) collaboration between the Directorates for Education and Human Resources (EHR) and Geosciences (GEO) under grant DUE - 1125331 


\section{InTeGrate: STEP Center Goals}

- To develop curricula that will dramatically increase Earth literacy of all undergraduate students

- To increase the number of majors in the geosciences and related fields who are able to work with other scientists, social scientists, business people, and policy makers to develop viable solutions to current and future environmental and resource challenges 


\section{InTeGrate: STEP Center Goals}

To support development \& dissemination of new model programs based on an understanding of current practice.

- Programs that engage students with interdisciplinary approaches to issues of sustainability.

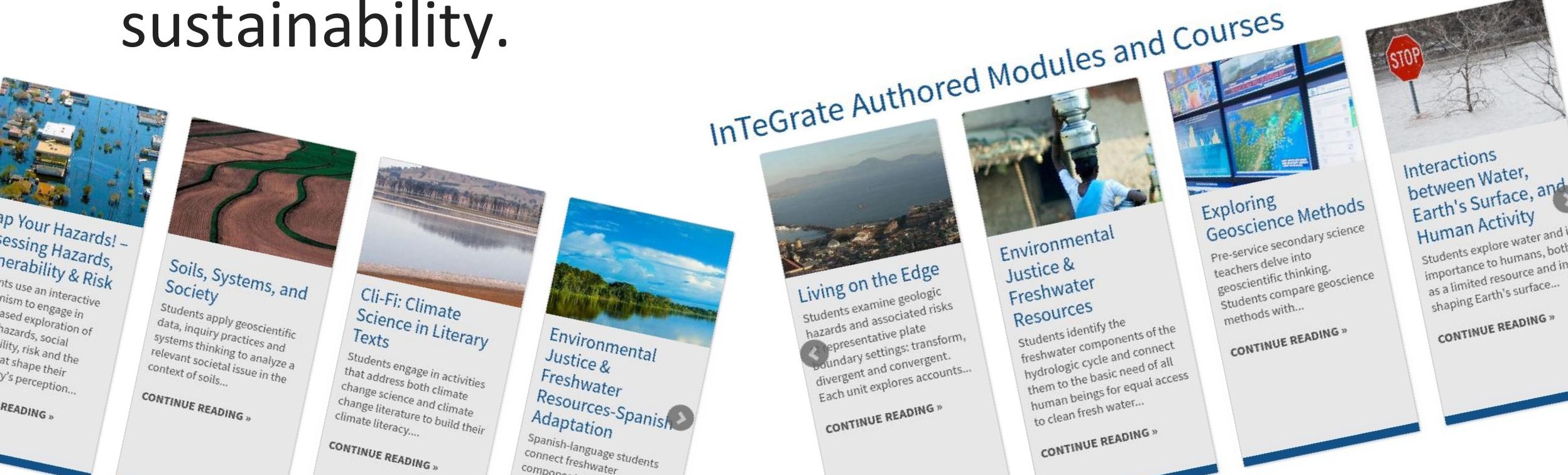




\section{InTeGrate: STEP Center Goals}

-Achieving these goals requires a revolution in how geo-education is perceived and practiced, as well as the roles that learning about the Earth play in the broader curriculum in institutions of higher education.

- Connecting geoscience education to societal challenges has the potential to increase enrollment in geoscience and allied courses, thus strengthening the field while serving society. 


\section{InTeGrate Materials}

- Teach students about Earth-related grand challenges facing societies through an interdisciplinary approach

- Have students work with authentic and credible geoscience data

- Develop students' abilities to solve interdisciplinary problems, increase proficiency in applying geoscientific thinking methods, and advance systems thinking skills 


\section{InTeGrate Reach}

\section{Distribution of Module/Course Authors} + Implementation Programs + Workshop Participants includes all 50 states, Puerto Rico, India, and Micronesia

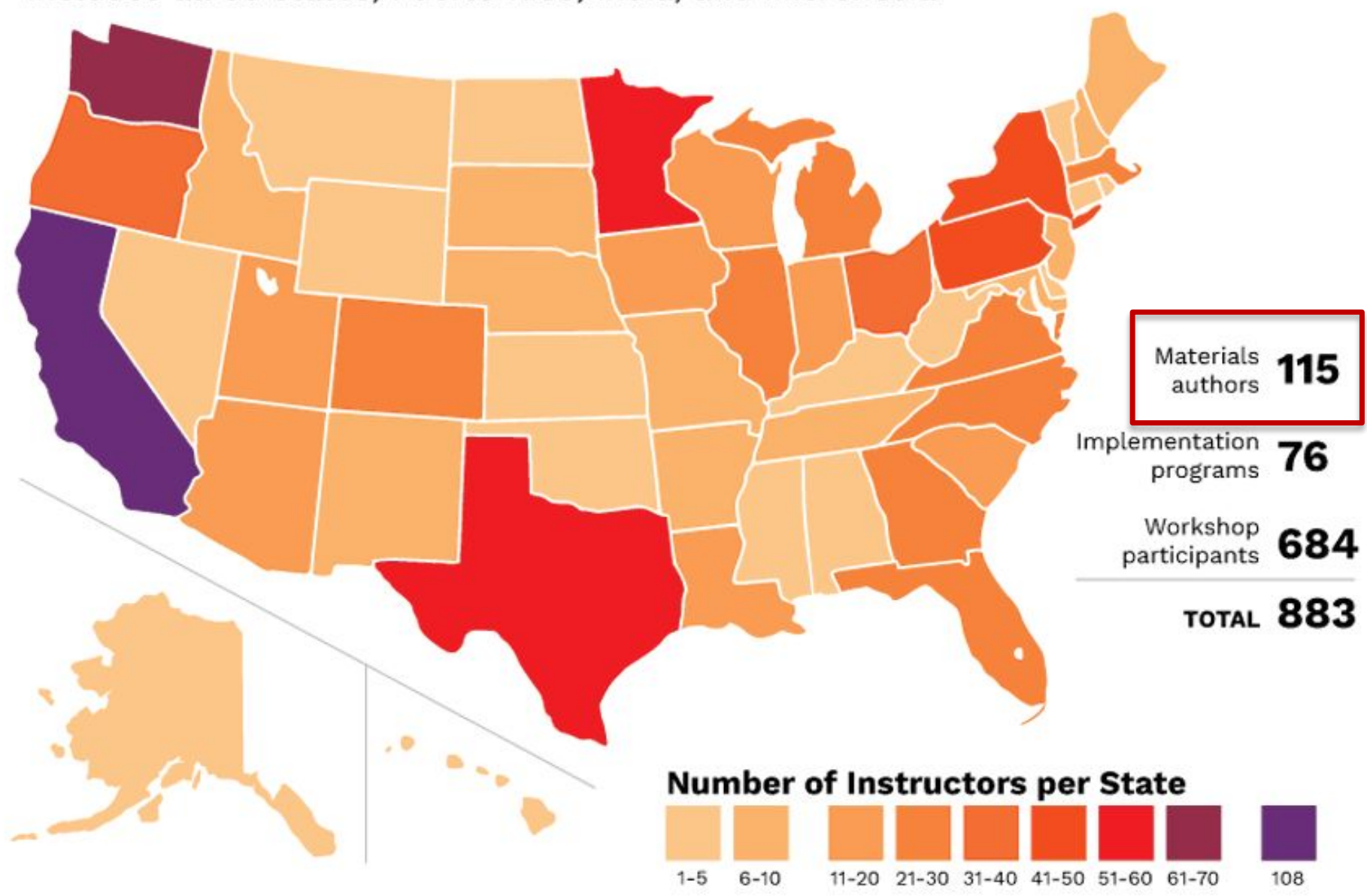


Two Year InTeGrate Materials Development Timeline

Pass Assessment

Rubric

Proposal

Accepted
Materials In Development

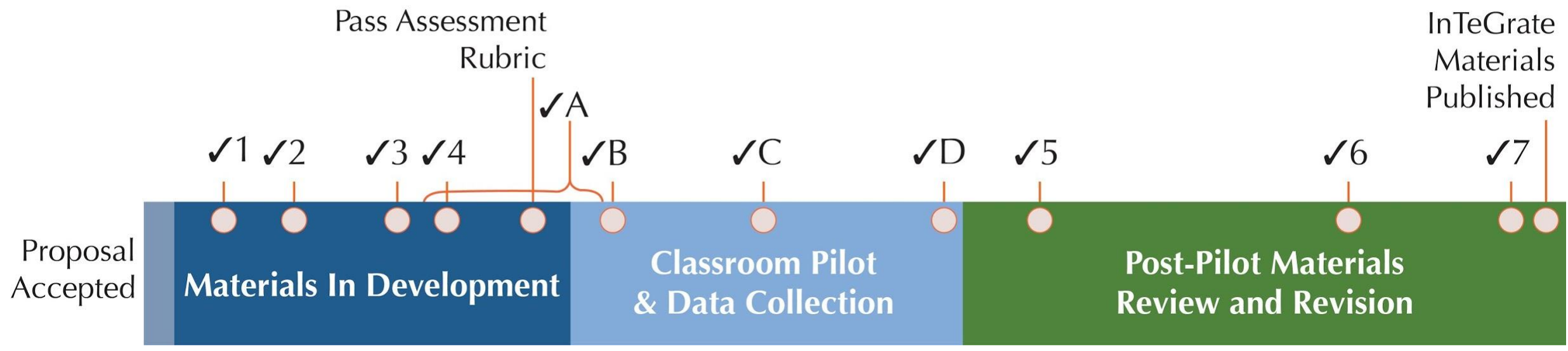

InTeGrate Materials Published

\section{Phase 1}

Checkpoint 1: Learning outcomes/assessment at face-to-face meeting

Checkpoint 2: Assessment consultant informal review ( $50 \%$ complete) Checkpoint 3: Assessment consultant scores materials using rubric Checkpoint 4: Three assessment consultants score materials 


\section{Materials Development Rubric}

\section{Six Major Parameters}

1. Overarching Goals (5 sub-elements)

2. Learning Objectives and Outcomes ( 5 sub-elements)

3. Assessment and Measurement (5 sub-elements)

4. Resources and Materials (6 sub-elements)

5. Instructional Strategies (5 sub-elements)

6. Alignment (2 sub-elements)

\section{Scoring}

3 points: rubric element pervasively addressed in module/course materials 2 points: rubric element addressed in majority of the module/course materials 1 points: rubric element addressed in some of the module/course materials 0 points: rubric element not addressed in the module/course materials 


\section{Materials Development Rubric}

Checkpoint 4: Materials Development Scoring

- Three-person review (scores assigned for each sub-element by each reviewer)

- Materials Assessment Consultant

- Two other Assessment Team members

- If two of the three scores matched, matching score assigned to sub-element

- Review team phone conference if major discrepancies

- Passing score $=100 \%$ for guiding principles; $85 \%$ for all other major categories 


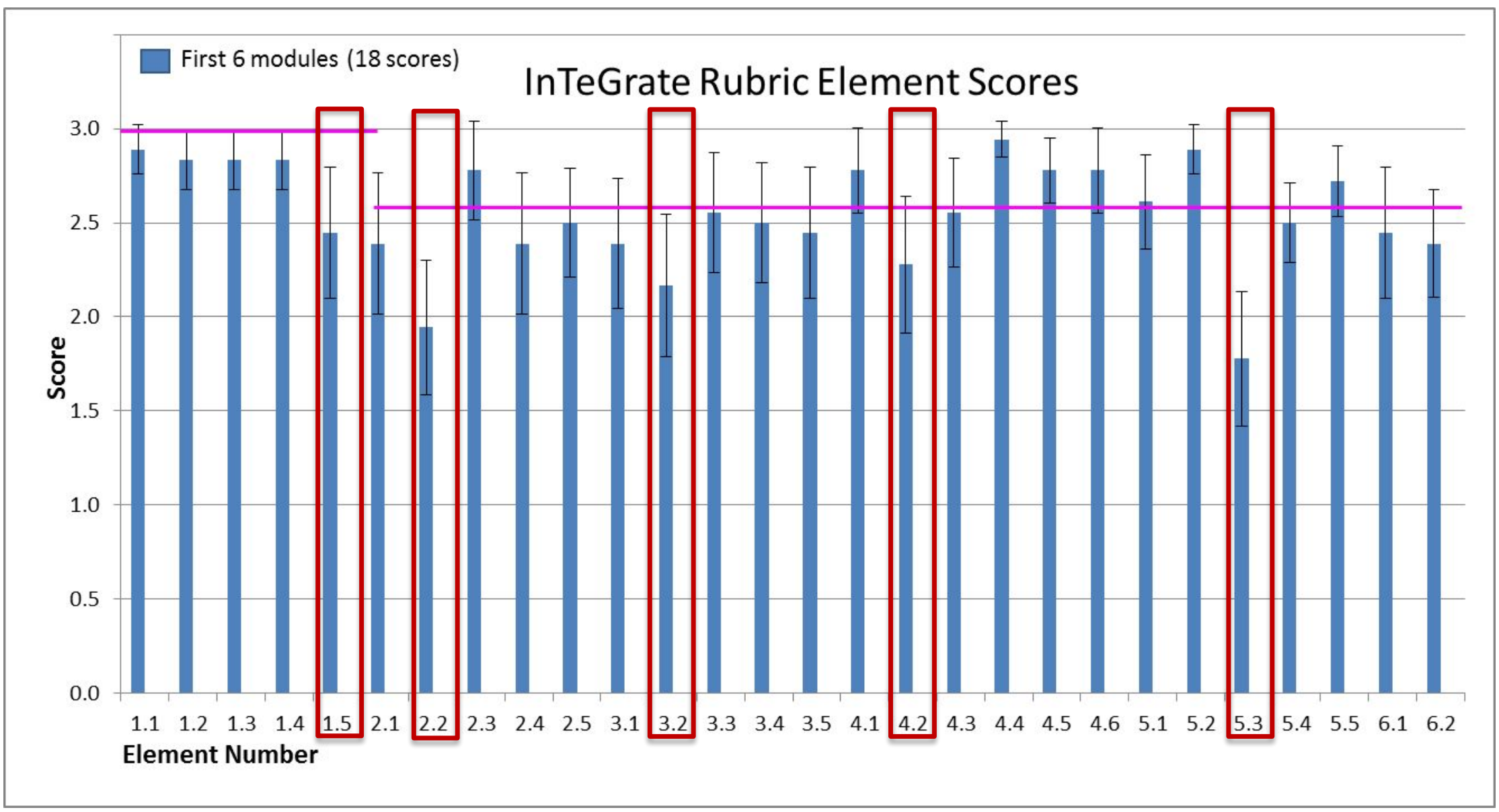

1.5 Systems Thinking 3.2 Criterion Referenced 5.3 Metacognition

2.2 Grading Rubrics 4.2 Materials Link 


\section{Professional Development}

- Assessment team discussed areas where module teams needed more support and co-scored some materials

- Future cohort authors' meetings were aligned to touch on major rubric elements

- Developed series of PD Webinars

- Using the Materials Development Rubric

- Developing Assessments and Grading Rubrics

- Incorporating Systems Thinking

- Implementing Metacognition Strategies 


\section{Second Cohort 1 minor revisions}

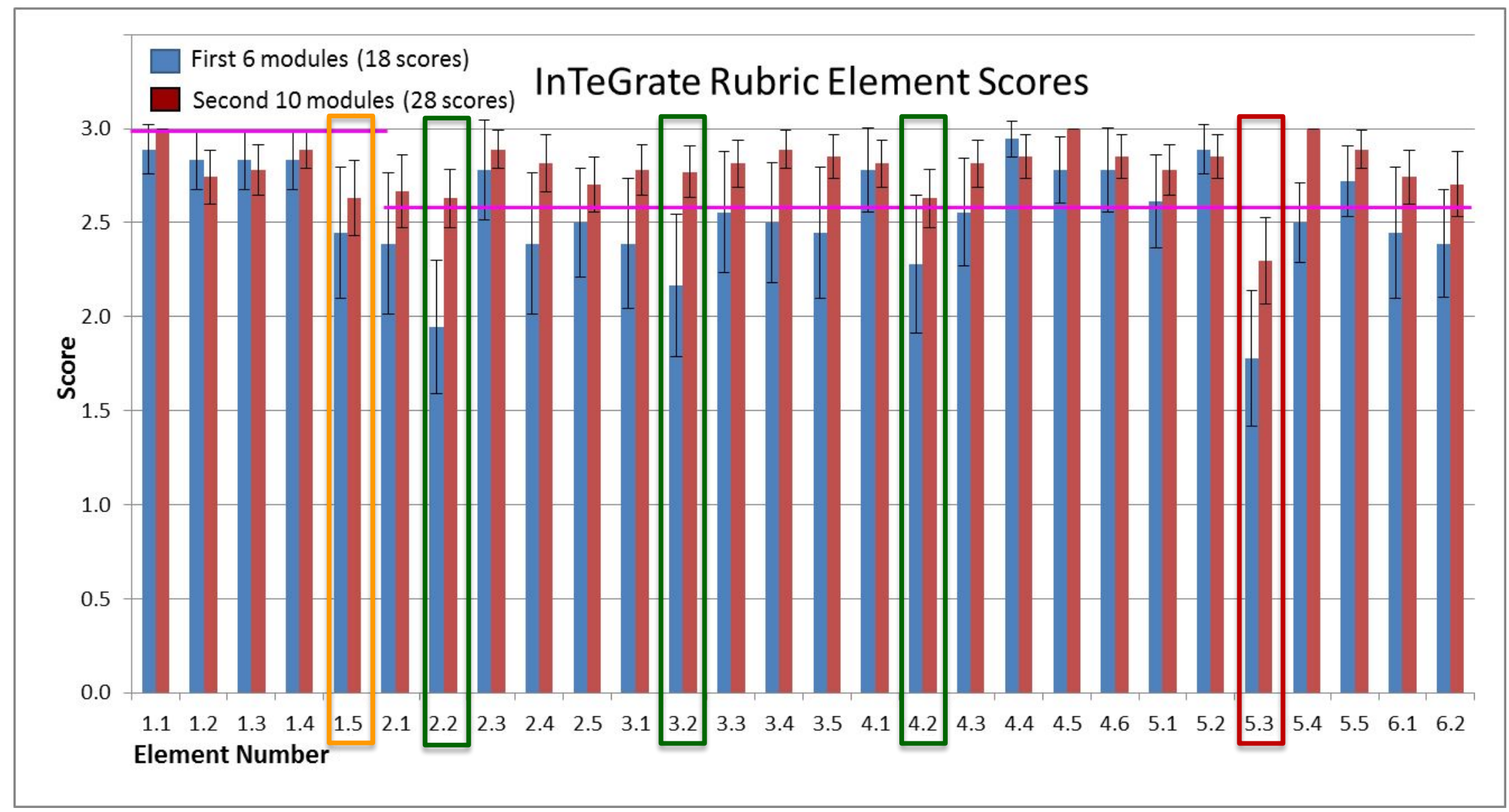

1.5 Systems Thinking 3.2 Criterion Referenced

2.2 Grading Rubrics

4.2 Materials Link

5.3 Metacognition 


\section{Why is Metacognition so difficult?}

- Deals with students' abilities to self assess and monitor their own learning

- Knowledge of procedures that affect own learning

- Regulation or selection of appropriate learning strategies

- Students (and faculty) often not aware they are engaging in these activities

- Generally not emphasized in curricular materials familiar to most faculty 
Two Year InTeGrate Materials Development Timeline

Pass Assessment

Proposal Accepted
Rubric

Materials In Development

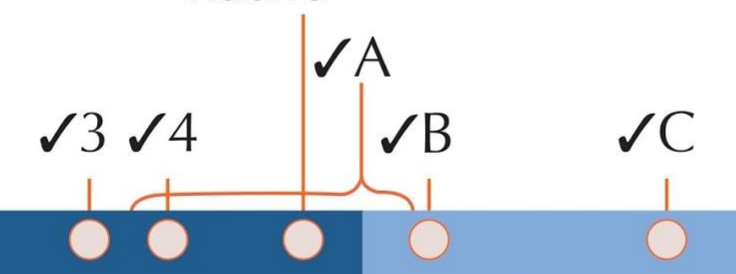

Classroom Pilot

\& Data Collection
InTeGrate

Materials Published

Phase 2: Classroom Pilot: Authors pilot materials in their own classroom and collect data that supports the evaluation of the team's materials, anecdotal information to be included on their instructor stories pages and the project's overall goals. 


\section{(IH) InTeGrate}

Two Year InTeGrate Materials Development Timeline

Pass Assessment

Proposal Accepted
Rubric

Materials In Development

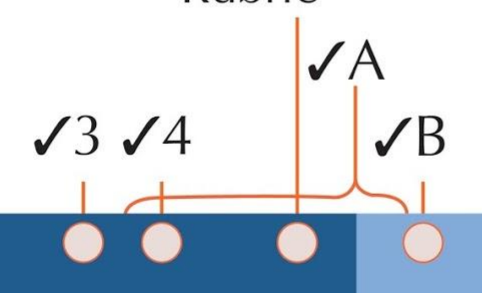

Classroom Pilot

\& Data Collection
InTeGrate

Materials

Published

\section{Phase 3: Post-Pilot Materials Revision: Author team uses data collected to make meaningful revisions to module/course materials.}




\section{Conclusions}

- Use of a materials development rubric with active coaching is an effective combination

- Many faculty members could benefit from professional development

- Systems thinking

- Grading rubrics with defined criteria

- Aligning materials, resources and assessments

- Metacognition 